\title{
POPULATION AGING AND THE MAINTENANCE OF SOCIAL SUPPORT SYSTEMS
}

\author{
Frank T. Denton and Byron G. Spencer
}

IESOP Research Paper No. 9

September 1996

The Program for Research on the Independence and Economic Security of the Older Population is an interdisciplinary research program established at McMaster University with support from Health Canada’s Seniors' Independence Research Program. The Research Paper series provides a vehicle for distributing the results of studies undertaken by those associated with the program. Authors take full responsibility for all expressions of opinion.

For further information about the research program and other papers in this series, see our web site at: http://socserv2.mcmaster.ca/ iesop/

Note: This paper is cross-listed as No. 320 in the McMaster University QSEP Research Report Series. 
September, 1996

\title{
Population Aging and the Maintenance of Social Support Systems*
}

\author{
Frank T. Denton and Byron G. Spencer \\ McMaster University
}

\begin{abstract}
The baby boom generation is now well into middle age, and over the next few decades will reach old age. As the boom generation grows old the costs of maintaining existing social support systems will rise, and the ability or willingness to sustain those systems has been called into question. In this paper we discuss a number of issues related broadly to population aging in Canada and the associated social “costs,” including the costs of public services. We conclude that while population-related cost increases should be expected, and reallocations of resources required, the overall increases should be of manageable proportions.
\end{abstract}

\section{Introduction}

The baby boom generation is now well into middle age, and over the next few decades will reach old age. That fact has given rise to widespread concern and called into question the ability and willingness to maintain social support systems, including, in particular, the publicly funded

* The authors thank Christine Feaver and Huan Nguyen-Dinh for their research assistance in connection with the preparation of this paper. 
income security and health care systems. The main features of those systems were in place by roughly the end of the baby boom, when it appeared that the costs associated with supporting the older members of the population were relatively low: fertility rates were still high by current standards and the population was both young and growing at a fast pace. Now, some three decades later, the situation is much different: fertility has fallen well below the replacement rate, life expectancy has increased considerably, the rate of population growth is much lower, and the population is aging. In consequence, the prospective costs associated with supporting the older population now appear to be high.

We discuss a number of issues related to population aging in Canada, and the social "costs,” broadly defined, including the costs of public services. We conclude that reallocations of resources will be required, but that overall the population-related cost increases should be of manageable proportions.

\section{How Much Aging Should Be Expected?}

The dating of the baby boom is somewhat arbitrary, but as an approximation, in 1996 the baby boom generation is between the ages of 30 and 50 (as represented by the shaded area in the upper portion of Figure 1). In 35 years, by 2031, it will thus be 65 and over (the shaded area in the lower portion). As that generation ages it will continue to account for a large fraction of the total population, and to have a marked impact on its character. For example, using projection assumptions that we label "medium" or "standard," the median age of the population will increase by almost 9 years, to age 44, and the median age of the labour force by about 3 years, to age 40. Furthermore, the population 65 and over will be about two and one-half times as large 
as it is now (9.2 million, compared to 3.7), and will account for almost a quarter of the total, up from one eighth. ${ }^{1}$ Alternative assumptions, especially those relating to fertility, have some impact on the share of the older population, but a considerable increase in that share seems all but certain over the next few decades. (See Denton, Feaver, and Spencer, 1996, for projections under a range of alternative assumptions.)

\section{How Much Will Aging Cost?}

There is no single measure of the "cost" of population aging, and it is helpful to consider some alternatives. One simple and widely used measure is the ratio of the total population to the population of "providers." That measure, which can be referred to as the dependency ratio, is a basic indicator of the ability of the society to support itself. The "providers" can be defined as either (1) the population in a specified age range (e.g., 20 to 64) or (2) those in the labour force. In what follows, we use the ratio of population to labour force as our measure of dependency, but similar results would be obtained if a strictly population-based measure were used instead.

The dependency ratio for the period 1951 through to 2031 is plotted in Figure 2. While considerable population aging can be expected, and indeed much aging has already occurred, the current dependency ratio is nonetheless very low, by historical standards, and for the next several decades will remain well below what is was in the 1960s and 1970s. While the proportion in old age (65 and over) is projected to increase sharply, the proportion of young people (under 20) is projected to decrease, with the net result only a modest rise in the overall dependency ratio. Note too that the ratio is projected to fall slightly for another decade or more, 
before rising gradually; by 2031 the ratio will once again be as high as it was in the late 1970s, but much lower than in the earlier post-war period.

How does the situation differ among the provinces? Figure 3 shows projected dependency ratios for selected provinces for the period 1996 to 2031, together with the Canada ratios reproduced from Figure 2. (The provinces selected are Newfoundland, New Brunswick, British Columbia, and Alberta, abbreviated NF, NB, BC, and AL in the figure.) Based on our "standard" assumptions, while the Canadian population 65 and over will more than double by 2031, the increase in Newfoundland will be almost four-fold, and the older population in that province will be nearly as large as the labour force itself. The outlook appears extreme in Newfoundland, but relatively rapid aging is projected also for New Brunswick. (The same is true of Nova Scotia and Quebec, although those provinces are not represented in Figure 3.) If present trends continue there will be notably less rapid aging in all provinces to the west of Quebec, the lowest projected ratios being those for British Columbia and Alberta. An important implication is that there are likely to be major differences among the provinces in their abilities to maintain social support systems.

More refined measures of dependency are possible; not all dependents need to be treated as equal. In particular, it may be that old dependents represent a greater "burden" than young ones, and should be given a greater weight in the calculations. (See, for example, Foot, 1989.) We have explored the question of just how much more "costly" those 65 and over would have to be than those under 20 in order that the (weighted) dependency ratio would reach levels in the future as high as those attained in the past. The answer is that the older population would have to be weighted about three times as heavily (Denton, Feaver, and Spencer, 1996). Such a 
difference in weights seems unrealistic.

Dependency ratios relate to overall “costs” -- costs from society's point of view -- and are not affected by whether such costs are borne publicly or privately. Alternative measures can be constructed that focus only on public expenditure and build on the observation that there are major differences in utilization between older and younger dependents. Older dependents obviously make more demands on the public health care and social security systems, younger dependents on the educational system.

Consider health care. If the current system is to be maintained -- if the society is to continue to make available to people in each age group, on average, the same levels of publicly funded health care services that they have had in the recent past -- it can confidently (and not surprisingly) be expected that health care costs will not only rise (in “real,” or constant-dollar terms), but will rise faster than the overall population. Some calculations that cover the period 1941 to 2031 are reported in Figure 4. The figure shows that while the projected population (POP) would increase by 50 percent between 1986 and 2031, publicly funded health care costs (HC) would double. $^{2}$

We can expect the cost of social security programs ${ }^{3}$ to rise also (in real terms), if current entitlement levels are maintained, and, as Figure 5 shows, the rise is likely to be much greater than for health care. Compared to a 50 percent increase in the population, expenditures on social security (SS) are projected to increase more than three-fold. ${ }^{4}$

Public expenditures on programs associated mostly with the young can be expected to increase by much less, to the extent that they reflect population change. Figure 6 displays the results for education (ED, representing all education levels combined); it indicates that 
population change alone would lead to an increase in expenditure of only about 10 percent by 2031. (It may be noted, from Figure 1, that the population under 20 is 8.0 million in both 1996 and 2031; thus the projected increases in public education costs result entirely from changes in age distribution within the under-20 population.)

The age-expenditure patterns considered so far are strongly skewed to either the older ages (health care and social security) or the younger ones (education). Others categories of public expenditure are associated with the population as a whole (e.g., national defence, general government services, firefighting) or relate mostly to ages between 20 and 65 (e.g., correction and rehabilitation services, unemployment insurance, workers' compensation). When age patterns (including uniform ones) are assigned to an exhaustive set of 72 government expenditure categories (all levels of government combined, and separately for goods and services, on the one hand, and transfers, on the other), and the projected expenditure level in each category is calculated so as to reflect only the course of population change, the resulting aggregate expenditure is as shown by the ALL line in Figure $7 .^{5}$ The line indicates, perhaps surprisingly, that the total expenditure necessary to maintain publicly provided services would increase at very much the same rate as the total population. Overall per capita expenditure would thus change very little.

Yet another measure of cost results from comparing projected public expenditure to the productive capacity of the economy, as represented by its gross domestic product. (The GDP itself is influenced by the size and age composition of the labour force, and hence by the age distribution of the population.) Recent projections that we have made (Denton and Spencer, 1995) indicate that, in consequence of population change alone, the publicly funded portion of 
health care costs would increase from 6.2 percent of GDP in 1991 to 8.9 percent in 2031, and social security costs would increase from 4.6 percent to 8.0 percent. Over the same period, education costs would decrease from 5.8 percent to 5.1 percent. Those three important categories together, then, would increase from 16.6 percent of GDP in 1991 to 22.0 percent in 2031, in consequence of population change. However, as Figure 7 shows, when account is taken of all categories, total expenditure is projected to rise less rapidly than either the population or the gross domestic product. Thus we conclude that while major reallocations of resources among expenditure categories will be needed because of population change, the overall increases in public expenditure should not be a major problem. It must be emphasised once again that this conclusion relates only to demographic influences. Governments may, of course, increase or reduce expenditures for reasons quite unrelated to changes in the population.

\section{How Can Society Cope with the Effects of Population Aging?}

We have argued that the overall cost increases associated with population aging should be manageable. Nonetheless, the question arises as to how best to cope with the increases. We offer the following.

\section{a. Understand the problem}

It is important that the "aging problem” be correctly understood so as to avoid misguided policies. As one example, it is a common misperception that historical cost increases for health care have been associated largely with population aging; in fact, they have been associated almost entirely with increased utilization of services, and only in small part with aging. (See, for example, Evans, 1995; Denton and Spencer, 1995.) 
At a broader level, it is generally perceived that Canada has a persistently slow rate of economic growth, by historical standards. While GDP per member of the population, in constant dollars, grew by 1.6 percent per year over the two decades ending in 1995 (a little over half the rate of the two decades ending in 1975), the growth of GDP per employed person was much slower -- only 0.9 percent per year, or a little under half the rate in the previous two decades. Output per capita (GDP/N; see Figure 8) has grown more rapidly than output per employed person (GDP/E), largely because of the rise in women's labour force participation (and hence in the overall participation rate, $\mathrm{L} / \mathrm{N}$ ), which more than offset the increase in the unemployment rate (and hence the fall in the employment rate, E/L). ${ }^{6}$ The long-term persistence of slower economic growth is, of course, intimately related to the increases in government deficits and debts, and it is the sizes of the deficits that now drive governments' economic agendas, in large measure. The underlying causes of this slower growth are a matter of debate, as are the solutions to the associated economic problems. The point that is important here is that those problems $\underline{\text { do }}$

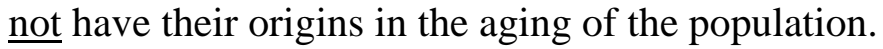

\section{b. Plan}

Social support systems require long-term planning, and one aspect of such planning is the anticipation of the likely consequences of demographic change. The health care system, for example, is intended to provide for the current and future health needs of the population. Those needs will be met through the availability of trained personnel (physicians, nurses, other health care professionals) and physical facilities (hospitals, nursing homes, etc.). If the needs are to continue to be met from the public purse, the provinces (which have the constitutional responsibility) should take an active role in determining the future numbers 
of entrants into education and training programs, how many beds will be available in different types of facilities, and so on. ${ }^{7}$ The public pays through various levies to maintain its health care system. It pays also to subsidize the training of health care personnel and for most of the capital and operating costs of health care institutions. Since the provision of health care services is not determined by market forces, it is up to governments to take an informed and leading role in health care planning, and for that a rather long view is required. (Newly trained personnel may be in the work force for four decades; newly constructed hospitals and other structures may be in use for even longer periods.) Moreover, health care should be considered as an integrated system, rather than piecemeal. Broadly similar remarks apply to the maintenance of educational institutions and the funding of social security systems.

\section{c. Who should be covered by old age social security programs?}

In planning for seniors the question of who fits into that category is of central importance; put differently, "how old is old ?"8 The answer to that question bears importantly on the matter of how costly publicly funded social security programs for the elderly will be in the future. According to the 1951 Canadian life tables, for example, males had a life expectancy at birth of 66.3 years and an expectancy at age 65 of 13.3 years; females had life expectancies of 70.8 at birth and 15.0 at age 65. In 1991, forty years later, life expectancy at birth for males had increased by 8.3 years, and at age 65 by 2.4 years; life expectancy for females at birth had increased by a full 10 years, and at age 65 by almost 5 years. If age 65 was appropriate for old age security eligibility in 1951, should the age of eligibility be higher now, and perhaps higher still in the future, as life expectancies continue to increase? 
Legislation enacted in the US stipulates that the age of eligibility for full old age social security benefits will increase, rising eventually to 67 , from its current level of 65 . Under the terms of that legislation, the 1937 birth cohort, which will be 65 in 2002, will be the last one eligible to receive full benefits at that age, while the 1960 birth cohort, which will be 67 in 2027, will be the first one not to receive full benefits until 67. An alternative approach, and one that is expected to be introduced in Sweden, is to index the benefit level to life expectancy (an increase in life expectancy would be associated with a lower annual benefit level), without changing the age of eligibility (Diamond, 1996, p. 69); equivalently, one could index the normal age of eligibility to life expectancy without changing the annual benefit level. ${ }^{9}$ However, if the age of eligibility of the older population for social security benefits were to be raised to reflect increased life expectancy there is the important related issue of retirement age. In many employment situations 65 is a legally enforceable mandatory age. It would make little sense for those who wished to continue working to be forced into retirement at 65 but not be eligible for benefits until, say, 67, or to be eligible only for reduced annual benefits. That would simply penalize people for the prospect of living longer. Retirement age and age of eligibility for benefits obviously need to be considered together.

\section{Summary and Concluding Remarks}

The baby boom generation is now in middle age, and in another three and one-half decades all its surviving members will be 65 or over; by conventional standards, all will be in old age. The population will then have two and one-half times more old people than it has now, and may account for a quarter of the total, compared with the current one eighth. Aging of the population 
has given rise to concerns about costs, and to questioning of whether the current social support systems can be sustained.

We have considered four types of measure of the cost of prospective population aging. The first is the standard or unweighted dependency ratio, which shows the size of the overall population relative to the labour force. The second is a weighted dependency ratio, in which old age groups and young age groups are weighted differently. The third is the projected government expenditure level that would be required to maintain the current provision of publicly provided services to persons in each age group as the population ages. The fourth is the third measure expressed as percentage of the productive capacity of the economy, as represented by its gross domestic product. Each of these measures indicates that the populationrelated cost increases should be of manageable proportions overall, in spite of the major shifts in age distribution that are in prospect. The basic challenge for the society is thus not how to cope with a massive overall increase in "dependency burden" or costs, but rather how to reallocate resources to match the changing requirements of the population as its age distribution evolves over the coming decades.

We have argued that society will be better positioned to maintain its social support systems if the "aging problem" is correctly understood, and if longer-term planning is brought to bear on the systems themselves, taking into account both future demands and the future productive capacity of the economy. Some of the demands are directly related to the legislated age at which older people become eligible for benefits. There may well be a case for raising the standard age of eligibility above 65 to reflect increased life expectancy. However, that should be done gradually, if at all, and consideration of it should take account of potential conflict with 
situations in which retirement at 65 is mandatory. Forcing people who wish to keep working to retire at 65 but reducing their social security benefit levels because the normal age of eligibility has been raised would penalize them for healthier life styles, improvements in medical science, and all the other factors that underlie the increase in the number of years that they can expect to live.

\section{ENDNOTES}

1. All projections are based on PMEDS-D, the demographic component of our economicdemographic projection system. In our standard projections, fertility rates remain at current levels, migration rates reflect continuations of recent experience, and mortality rates continue to decline, in line with historical patterns. These assumptions are maintained later when we consider provincial population projections, at which point the assumption that interprovincial migration will reflect recent experience is also invoked. When labour force projections are required, they are based on participation rates that reflect recent historical trends. More detailed information about the assumptions is available from the authors.

2. Included in health care are hospital, medical, preventive, and other health care expenses paid by governments; a more detailed discussion, based on an earlier population projection, is provided in Denton and Spencer (1995).

3. Social security programs here include the Canada Pension Plan, the Quebec Pension Plan, and the Old Age Security Program.

4. The expenditure profiles on which these calculations are based were developed before the introduction of OAS claw-back provisions; taking those provisions into account would reduce somewhat the projected cost increases.

5. See Denton and Spencer (1985) for more detail on the expenditure categories used.

6. The simple identity connecting the variables plotted in Figure 8 is $(\mathrm{GDP} / \mathrm{N})=(\mathrm{GDP} / \mathrm{E})$ $\mathrm{x}(\mathrm{E} / \mathrm{L}) \mathrm{x}(\mathrm{L} / \mathrm{N})$. Our discussion in based on that identity.

7. See Denton, Gafni, and Spencer (1994, 1995a, 1995b) for discussion of a model-based system designed to assist in planning how to meet future population health care requirements. 
8. See Denton and Spencer (1996) for a detailed discussion and the application of a number of alternative life table criteria to the definition of old age.

9. Differences between male and female life expectancies, and changes in those expectancies, raise some interesting questions from the point of view of indexing of this kind. Presumably, though, the differences would be ignored. 


\section{REFERENCES}

Barer, Morris L., Robert G. Evans, and Clyde Hertzman (1995), "Avalanche or Glacier?: Health Care and the Demographic Rhetoric,” Canadian Journal on Aging, Vol. 14, No. 2, pp. 193-224.

Denton, Frank T., Christine H. Feaver, and Byron G. Spencer (1996) "The Future Population of Canada and Its Age Distribution," McMaster University Program for Research on the Independence and Economic Security of the Older Population (IESOP) Research paper No. 3.

Denton, Frank T., Amiram Gafni, and Byron G. Spencer (1994) "System for Health Area Resource Planning (SHARP): An Application to Ontario Medical School Enrolment,” Canadian Medical Association Journal, Vol. 151, no. 1, pp. 39-45.

Denton, Frank T., Amiram Gafni, and Byron G. Spencer (1995a) "Physician Supply in Ontario: Further Observations on SHARP and the SHARP Projections," Canadian Medical Association Journal, Vol. 152, no. 9, pp. 1389-91.

Denton, Frank T., Amiram Gafni, and Byron G. Spencer (1995b) “The SHARP Way to Plan Health Care Services: A Description of the System and Some Illustrative Applications in Nursing Human Resource Planning,” Socio-Economic Planning Sciences, Vol. 29, No. 2, pp. 125-37.

Denton, Frank T., and Byron G. Spencer (1985) "Prospective Changes in Population and Their Implications for Government Expenditures," in Thomas J. Courchene, David W. Conklin, and Gail C.A. Cook, editors, Ottawa and the Provinces: The Distribution of Money and Power, Vol. 1 (Ontario Economic Council Special Research Report).

Denton, Frank T., and Byron G. Spencer (1995) "Demographic Change and the Cost of Publicly Funded Health Care,” Canadian Journal on Aging, Vol. 14, No. 2, pp. 174-92.

Denton, Frank T., and Byron G. Spencer (1996) "How Old Is Old? Revising the Definition Based on Life Table Criteria," McMaster University Program for Research on the Independence and Economic Security of the Older Population (IESOP) Research paper No. 2.

Diamond, Peter A. (1996) "Proposals to Restructure Social Security," The Journal of Economic Perspectives, Vol 10, No. 3, pp. 67-88.

Foot, David (1989) "Public Expenditures, Population Aging and Economic Dependency in Canada, 1921-2021,” Population Research and Policy Review, Vol. 8, pp. 97-117. 
Figure 1. Population Age Pyramids, Canada, 1996 and 2036

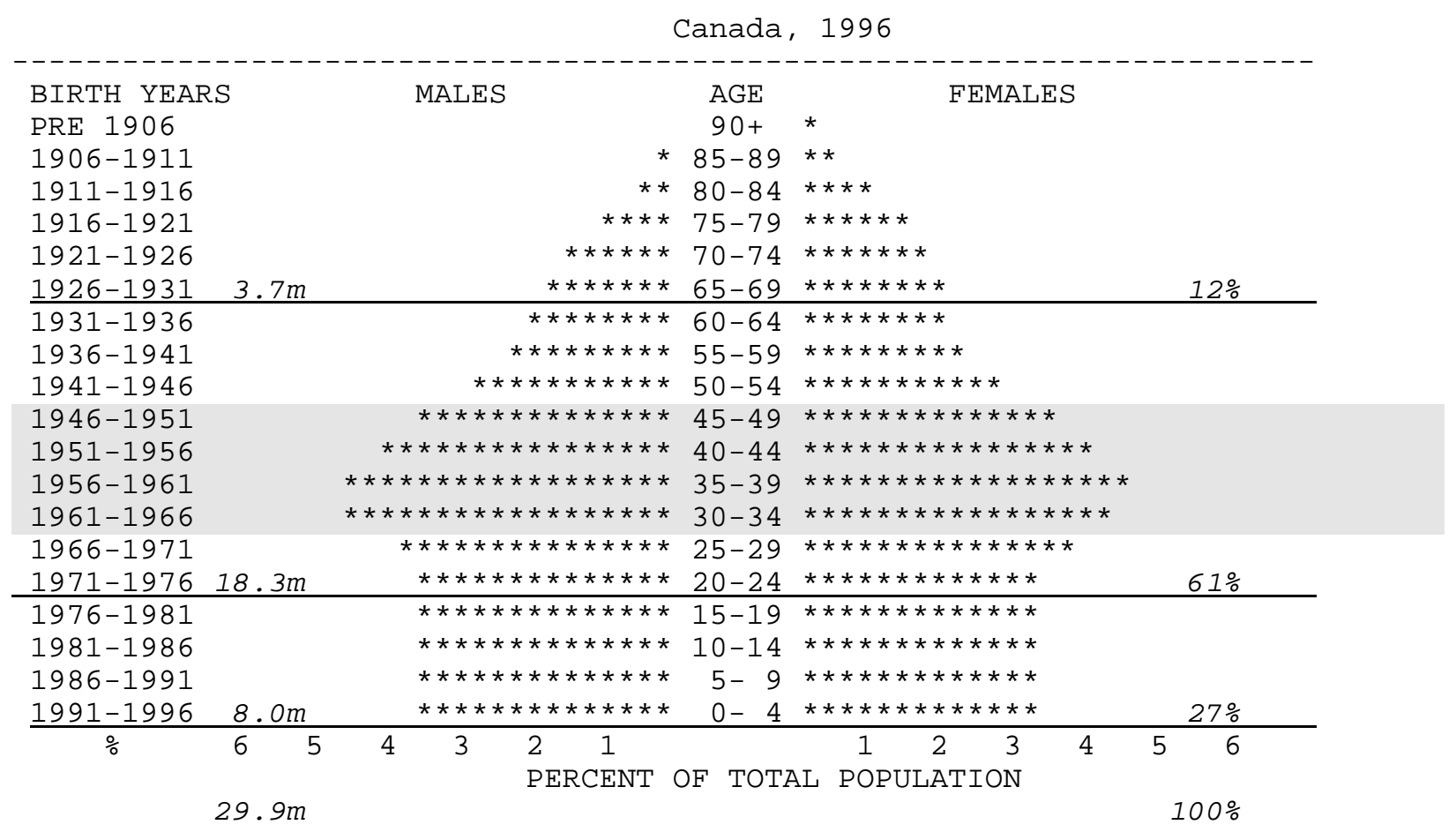

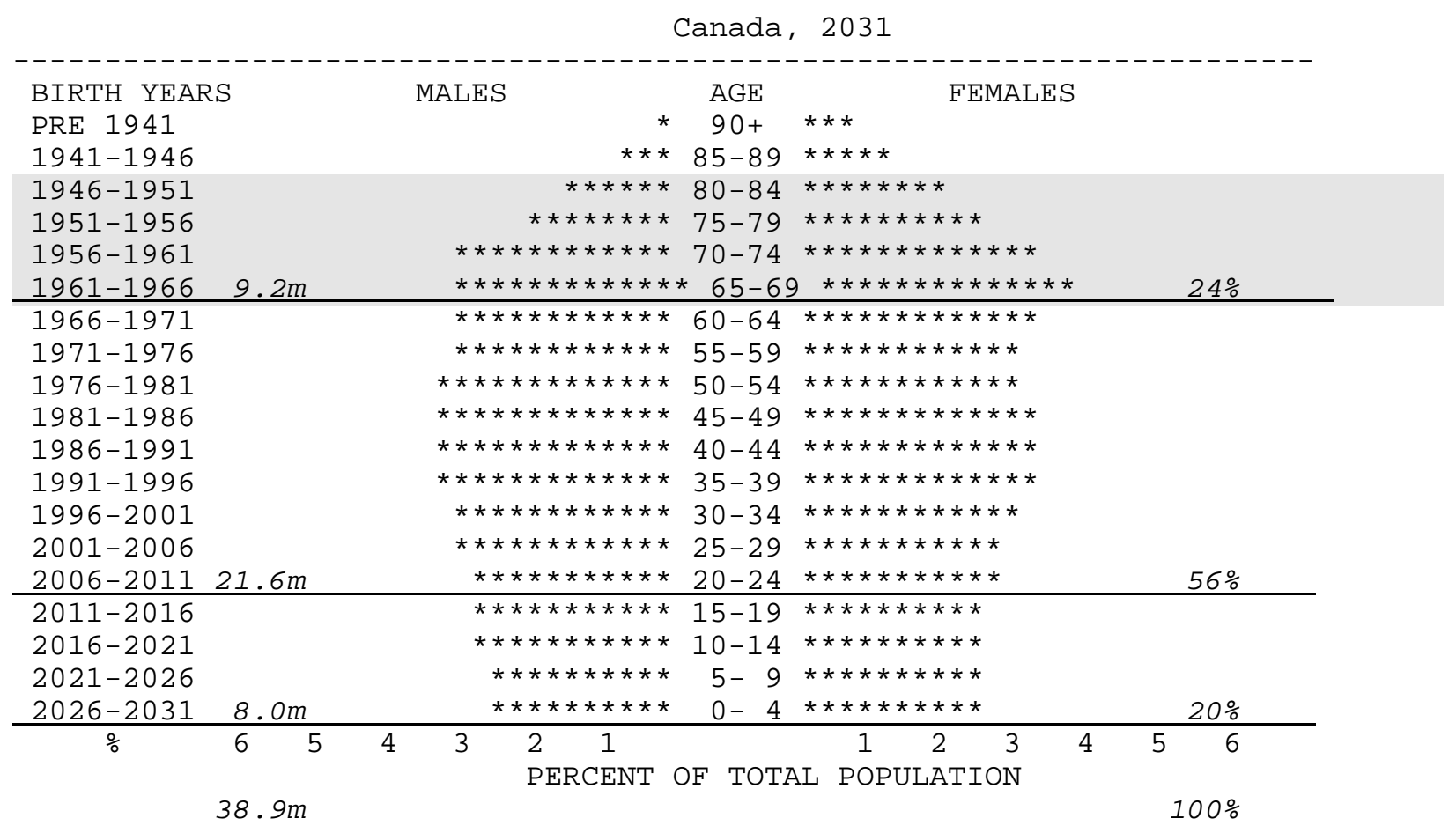

Note: The population in the "old," "provider,", and “young” age groups, as well as the total, are shown in millions, in italics, to the left of the pyramids, and the corresponding percentage distributions in italics to the right. 
Figure 2. Dependency Ratio, Canada, 1951 - 2031

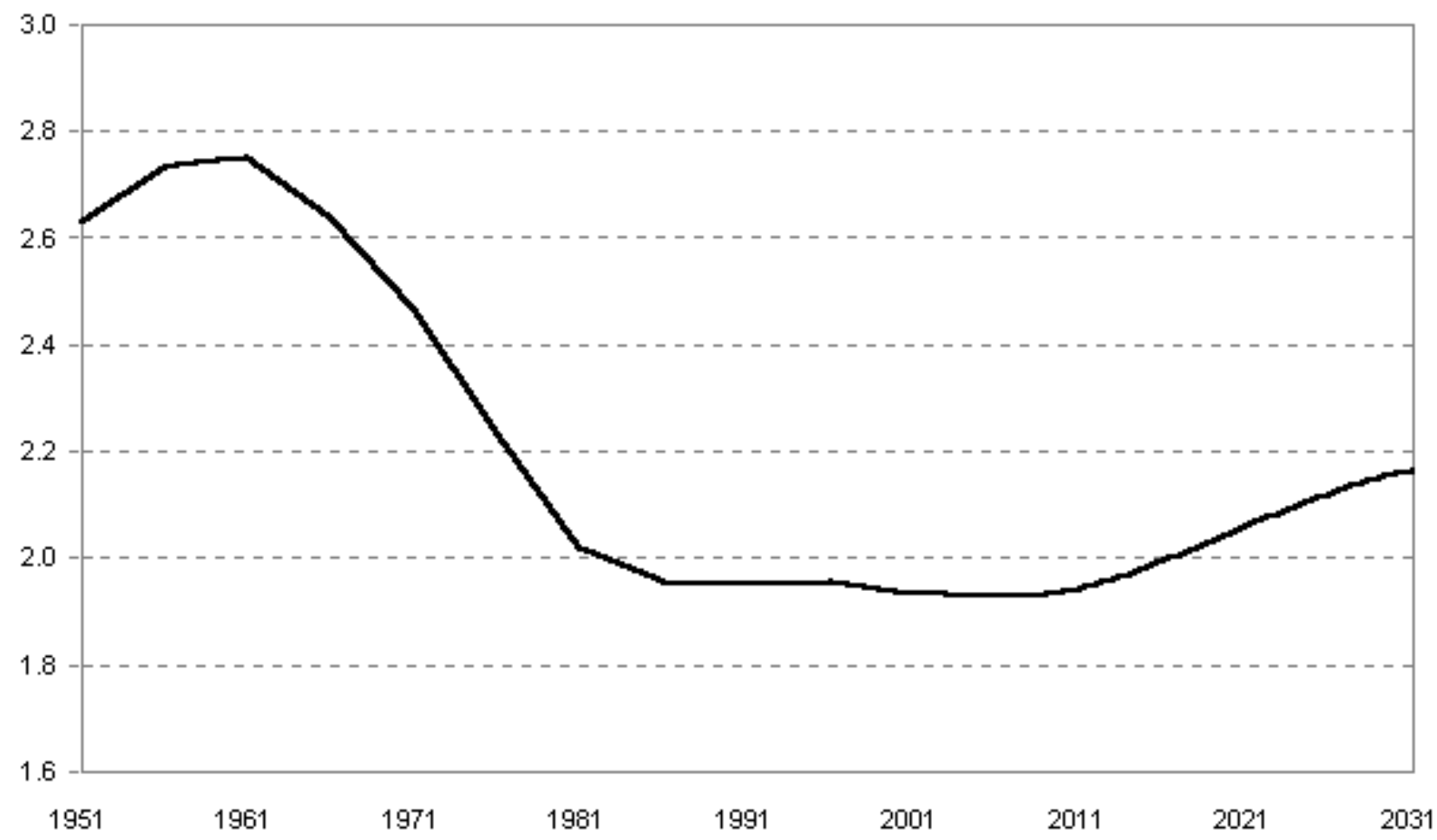

Source: Historical values for 1951-91 are based on data from Statistics Canada sources; values after 1991 are based on the PMEDS-D standard projection (see endnote 1). 
Figure 3. Dependency Ratios, Canada, 1951 - 2031, and Selected Provinces, 1996 - 2031

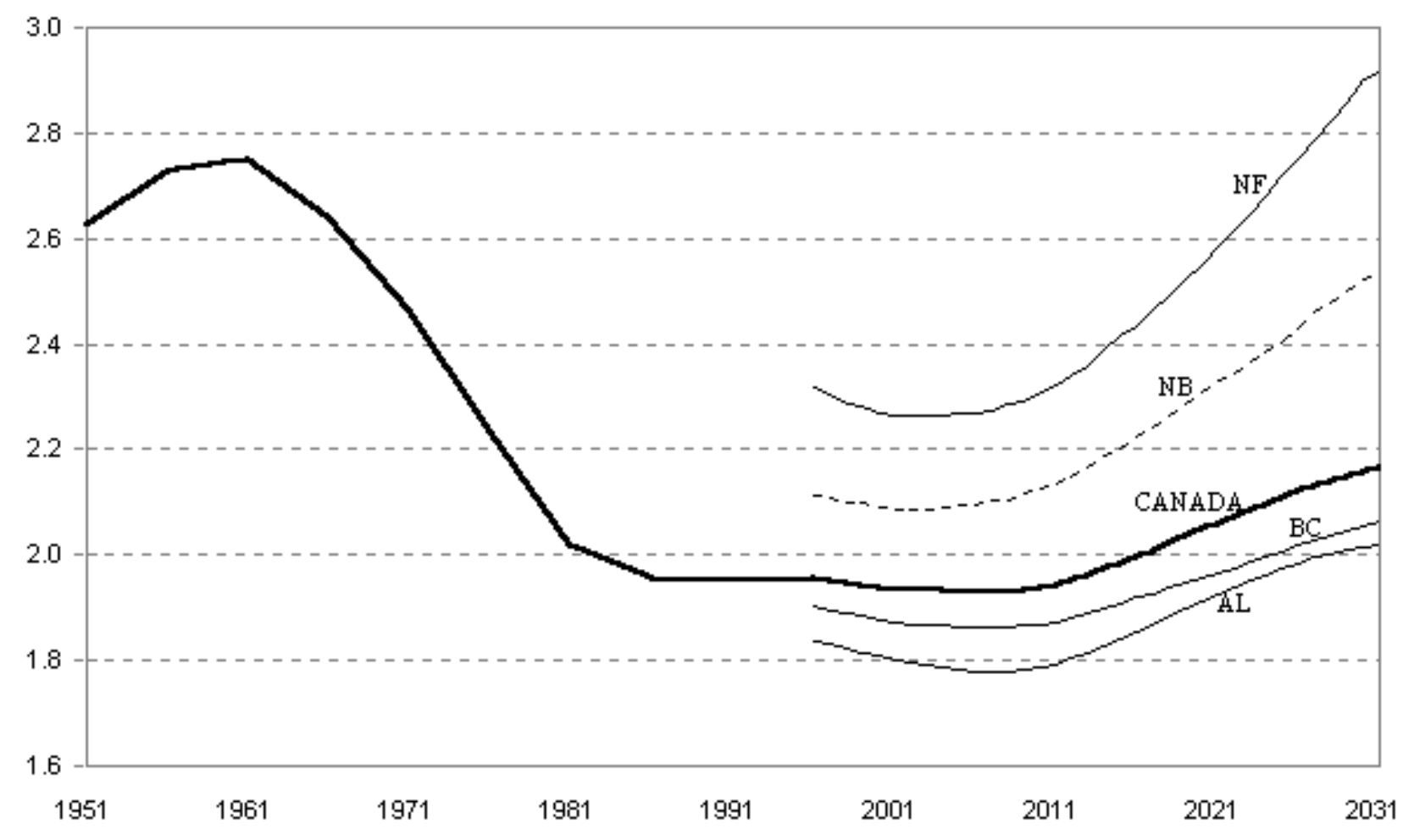

Source: See note to Figure 2. 
Figure 4. Constant Dollar Budgets Needed to Maintain 1986 Levels of Public Expenditure on Health Care in Each Age Group Over the Period 1941 - 2031 (Indexes, 1986=100)

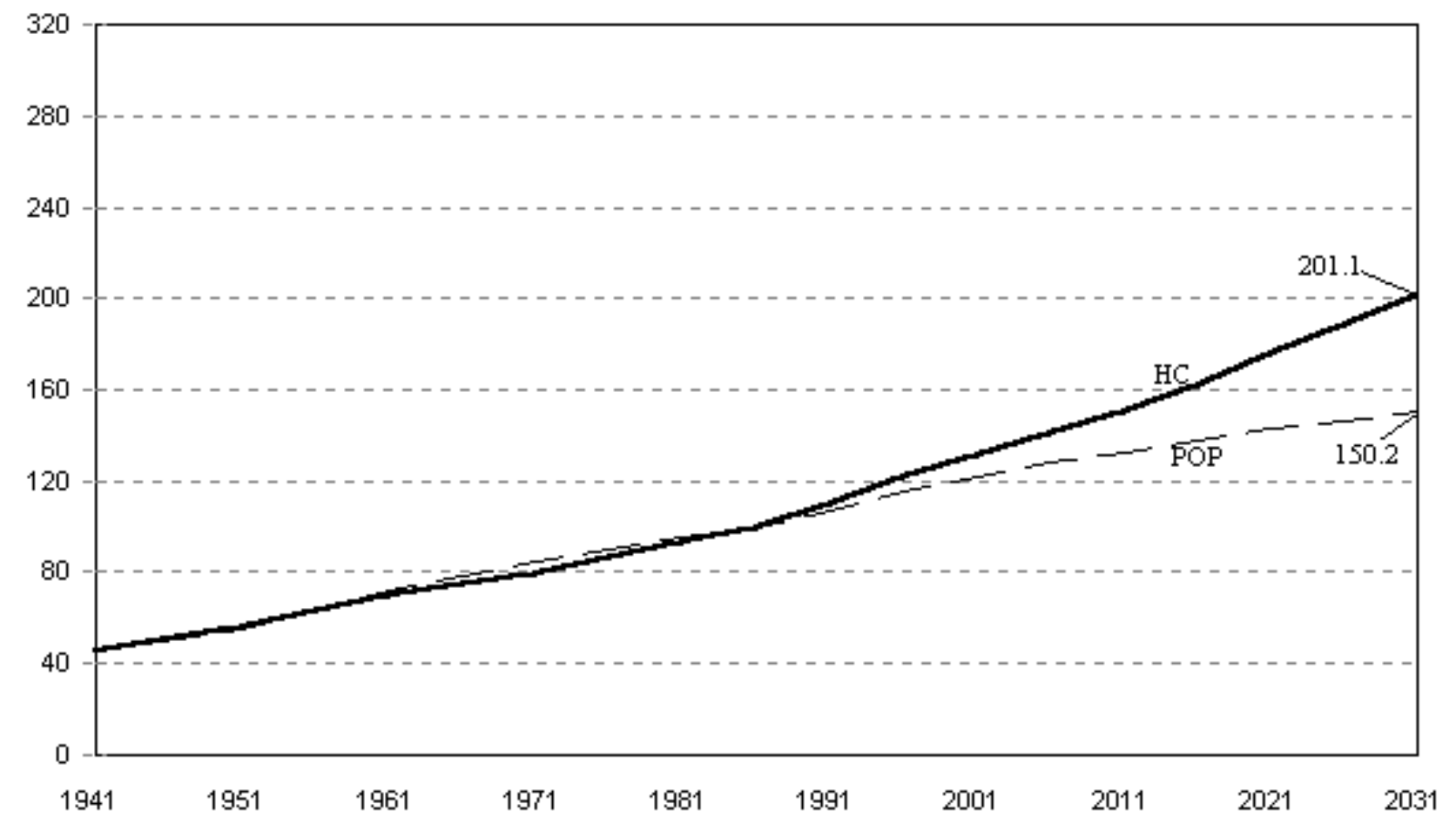


Figure 5. Constant Dollar Budgets Needed to Maintain 1986 Levels of Public Expenditure on Social Security in Each Age Group Over the Period 1941 - 2031 (Indexes, 1986=100)

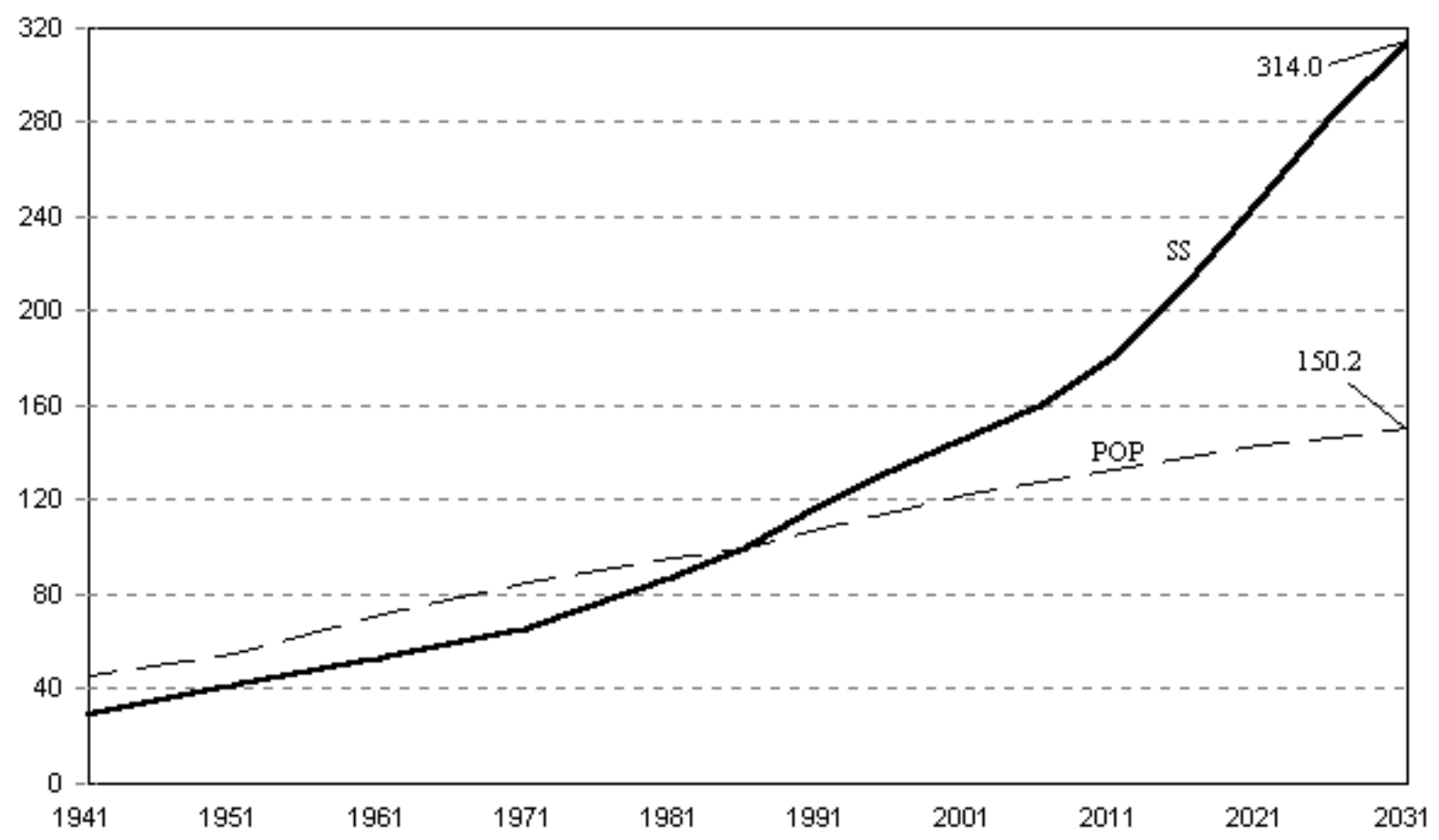


Figure 6. Constant Dollar Budgets Needed to Maintain 1986 Levels of Public Expenditure on Education in Each Age Group Over the Period 1941 - 2031 (Indexes, 1986=100)

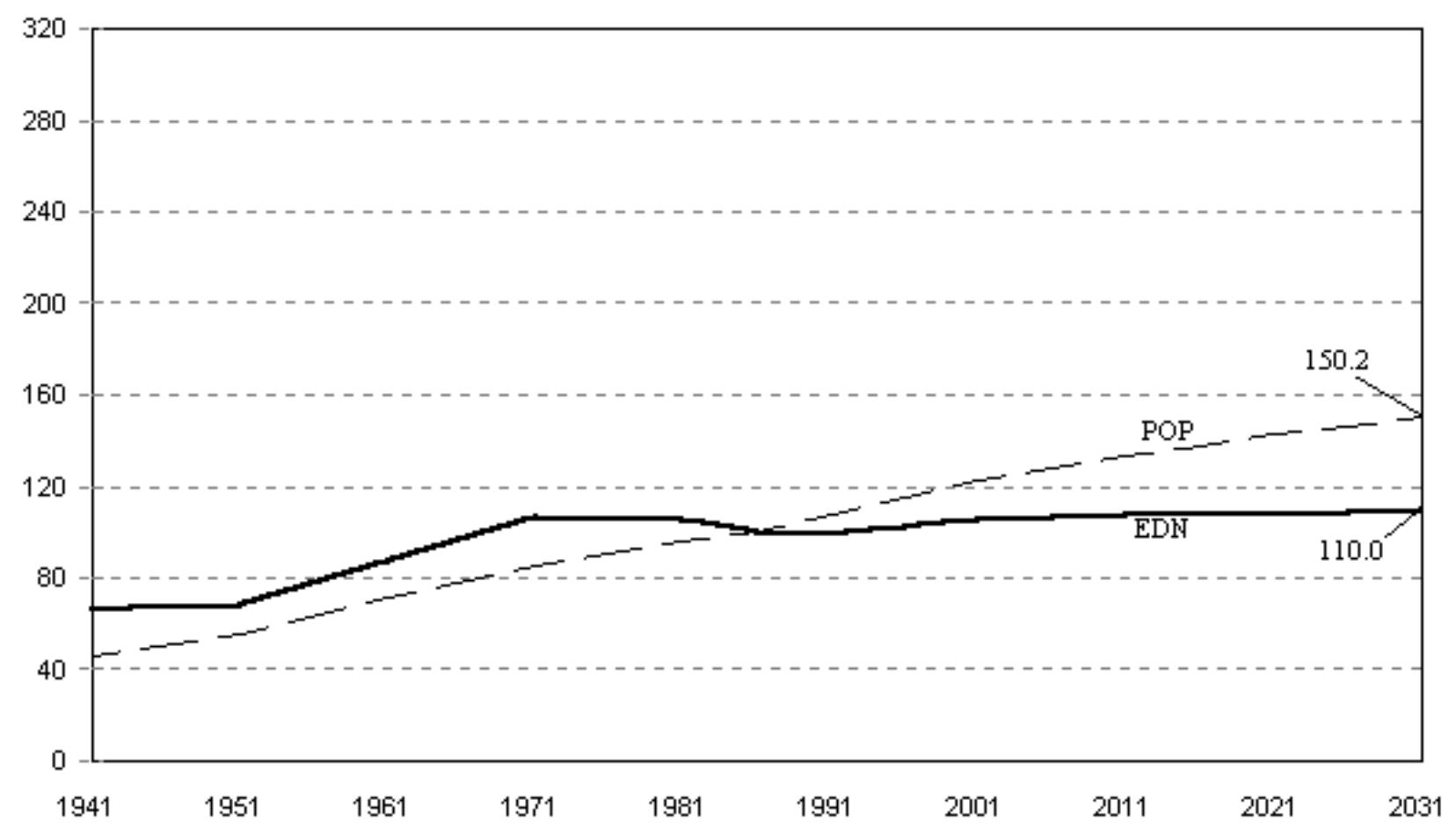


Figure 7. Constant Dollar Budgets Needed to Maintain 1986 Levels of Public Expenditure on Selected Budget Categories in Each Age Group Over the Period 1941 - 2031 (Indexes, 1986=100)

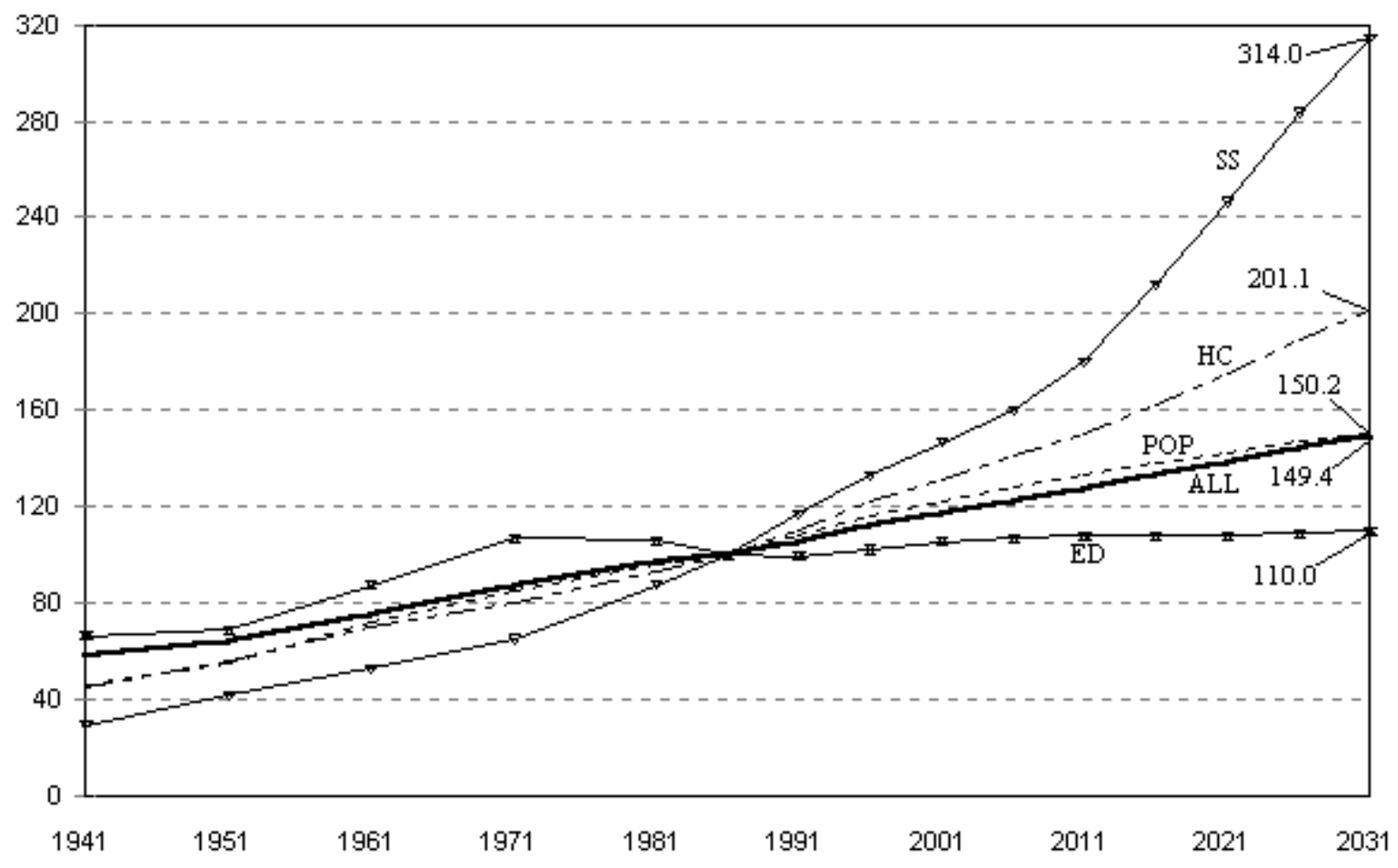


Figure 8. Analysis of GDP per Capita, 1970 - 1995 (Indexes, 1975=100)

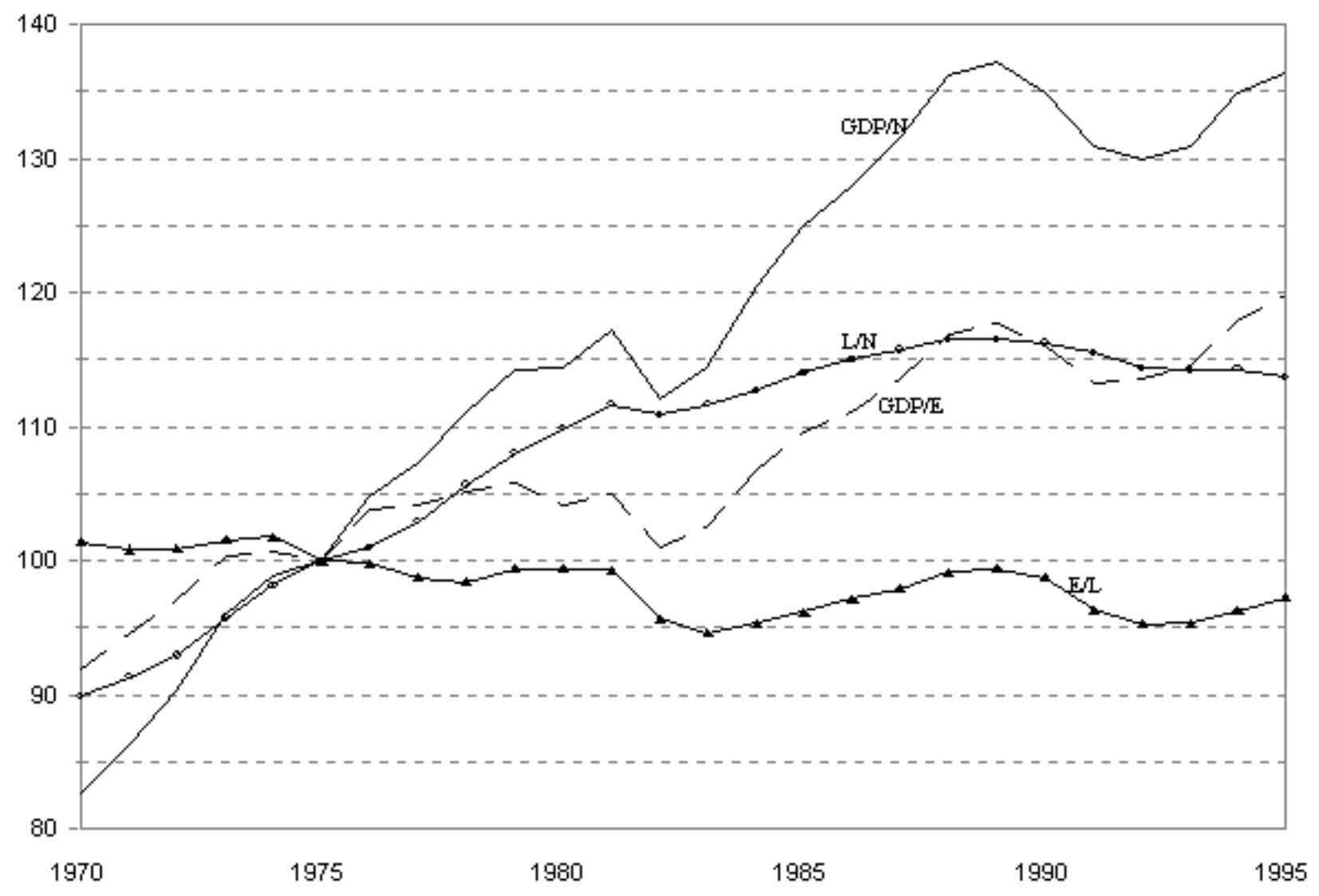




\begin{tabular}{llc}
\hline Number & Title & Author(s) \\
\hline
\end{tabular}

(1996)

No. 1: $\quad$ Public Pensions in Canada

J.B. Burbidge

No. 2: $\quad$ How Old Is Old? Revising the Definition Based on Life Table Criteria

F.T. Denton

B.G. Spencer

No. 3: The Future Population of Canada and Its Age Distribution

F.T. Denton

C.H. Feaver

B.G. Spencer

No. 4: $\quad$ Caught in the Middle? Occupancy in Multiple Roles and Help to Parents in a National Probability Sample of Canadian Adults

No. 5: Women, Work and Caregiving: How Much Difference Does a Great Job Really Make?

C.J. Rosenthal

A. Martin-Matthews

S.H. Matthews

A. Martin-Matthews

C.J. Rosenthal

No. 6: Health and the Transition from Employment to Retirement

V.W. Marshall

P.J. Clarke

No. 7: $\quad$ Aging and Work in Canada: Firm Policies

V.W. Marshall

J.G. Marshall

No. 8: The Changing Economic Circumstances of the Older Population:

A Cohort Analysis

F.T. Denton

B.G. Spencer

No. 9: $\quad$ Population Aging and the Maintenance of Social Support Systems

F.T. Denton

B.G. Spencer 